Moustafa A. Hamoud, Karam F. Allan, Refaat R. Ayoub, Mohamed Holeil and

Mamdoh R. Mahmoud*

\title{
Efficient removal of radiocobalt and manganese from their binary aqueous solutions by batch adsorption process using PAN/HDTMA/KCUHCF composite
}

https://doi.org/10.1515/ract-2020-0078

Received July 21, 2020; accepted October 5, 2020;

published online November 6, 2020

\begin{abstract}
Simultaneous removal of radiocobalt and manganese by adsorption onto polyacrylonitrile/hexadecyltrimethylammonium bromide/potassium copper hexacyanoferrate (PAN/HDTMA/KCuHCF) composite was studied. The synthesized composite was characterized by Fourier-transformed infrared (FT-IR), thermogravimetric analysis (TGA) and X-ray diffraction (XRD). The influence of the solution $\mathrm{pH}$ was studied in the range 1.5-7.8 and the results showed the effectiveness of the synthesized composite for simultaneous adsorption of radiocobalt and manganese in the $\mathrm{pH}$ range 2.5-6 at an adsorbent mass of $4 \mathrm{~g} / \mathrm{L}$. Adsorption kinetic data of manganese at the studied concentrations were best fitted by pseudo-secondorder kinetic model and the diffusion study showed that the adsorption process was controlled by film diffusion. Thermodynamic parameters $\left(\Delta \mathrm{G}^{\circ}, \Delta \mathrm{H}^{\circ}\right.$ and $\left.\Delta \mathrm{S}^{\circ}\right)$ were estimated and the results indicated that adsorption processes of the concerned (radio)toxicants were spontaneous and endothermic in nature. Of the studied isotherm models, Freundlich and Langmuir were the best ones for describing the adsorption isotherm data of radiocobalt and manganese, respectively. The adsorption capacity of PAN/HDTMA/KCuHCF was found to be 23.629 (for radiocobalt) and 62.854 (for manganese). Desorption of Radiocobalt and manganese loaded onto PAN/HDTMA/ KCuHCF composite was studied using various desorbing agents at different concentrations.
\end{abstract}

*Corresponding author: Mamdoh R. Mahmoud, Nuclear Chemistry Department, Hot Laboratories Center, Egyptian Atomic Energy Authority, P.0. Box 13759, Inshas, Cairo, Egypt,

E-mail:mamdohrefaat@yahoo.com

Moustafa A. Hamoud, Karam F. Allan, Refaat R. Ayoub and Mohamed Holeil, Nuclear Chemistry Department, Hot Laboratories Center, Egyptian Atomic Energy Authority, P.O. Box 13759, Inshas, Cairo, Egypt
Keywords: adsorption; hexacyanoferrate; manganese; polyacrylonitrile; radiocobalt.

\section{Introduction}

Radiocobalt, ${ }^{60} \mathrm{Co}$, is a well-known toxic radioactive element because of its relatively long half-life and high energy of gamma emission [1]. Therefore, it is vital to be concerned. Besides its radiotoxicity, cobalt possesses chemical toxicity which includes diarrhea, paralysis, lung irritations and bone defects [2]. On the other hand, the intake of manganese heavy metal resulted generally in serious health problems particularly for nervous and blood systems and thus it is considered one of the recognized contaminants. Permanganate $\left(\mathrm{MnO}_{4}^{-}\right)$, one of manganese species, is a toxic and aquatic organisms-threatening species. At low concentrations, permanganate solution can damage the gastrointestinal tract and can even be fatal. Relatively high concentrations of this solution cause throat swelling, suffocations and anemia [3]. In radioactive liquid waste, ${ }^{60} \mathrm{Co}$ and ${ }^{54} \mathrm{Mn}$ radionuclides are found as activation products derived from nuclear reactor materials $[4,5]$. It is reported that these radionuclides are still contained in the decontaminated water after the conventional decontamination processes $[6,7]$. Taking into consideration the abovementioned detrimental effects, it is a very crucial to remove cobalt and manganese from their binary aqueous solutions.

A lot of publications are reported on the removal of radionuclides by various treatment technologies such as chemical precipitation, solvent extraction, adsorption, membrane processes, reverse osmosis and foam separation [8-10]. Nevertheless, most of these publications are concerned with the removal of a single type of species, either cationic or anionic, and few studies are reported on removal of cationic and anionic contaminants from their binary aqueous solutions. Mahmoud and co-authors succeeded to simultaneously remove ${ }^{134} \mathrm{Cs}^{+}$and $\mathrm{HCrO}_{4}^{-}[11]$, ${ }^{60} \mathrm{Co}^{2+}$ and $\mathrm{HCrO}_{4}^{-}[12]$ and ${ }^{137} \mathrm{Cs}^{+}$and ${ }^{99} \mathrm{TcO}_{4}^{-}$[13] by 
adsorption process using polyacrylonitrile/ferrocyanide composite incorporated with cetrimonium bromide, 8-hydroxyquinoline-5-sulfonic acid-modified MCM-41 and silica/ferrocyanide composite, respectively. By foam separation technique, Mahmoud and Lazaridis [14] efficiently removed ${ }^{63} \mathrm{Ni}^{2+}$ and ${ }^{51} \mathrm{CrO}_{4}{ }^{2-}$ from radioactive process wastewater. A two-step method combining adsorption and photoreduction was applied by Yan et al. [15] for simultaneous removal of $\mathrm{Cu}^{2+}$ and $\mathrm{Cr}_{2} \mathrm{O}_{7}^{2-}$. Simultaneous removal of $\mathrm{As}^{3+}$ and $\mathrm{SO}_{4}{ }^{2-}$ was investigated by Matos et al. [16] using immobilized non-traditional sulfate-reducing bacteria mixed culture and alternative low cost carbon sources. Li et al. studied the simultaneous removal of $\mathrm{Tl}^{+}$ and $\mathrm{Cl}^{-}$using modified ion exchange resins [17]. Yan et al. evaluated the simultaneous adsorption of $\mathrm{Cd}^{2+}$ and $\mathrm{HAsO}_{4}{ }^{2-}$ from metallurgical wastewater using titanium dioxide, nanoscale zero-valent iron, granular ferric oxide and activated alumina [18]. Bifunctional mesoporous silica adsorbent was synthesized by Chen et al. [19] for simultaneous removal of $\mathrm{Pb}^{2+}$ and $\mathrm{NO}_{3}{ }^{-}$. Simultaneous removal and recovery of $\mathrm{Cd}^{2+}$ and $\mathrm{CN}^{-}$from simulated electroplating rinse wastewater by a strip dispersion hybrid liquid membrane containing double carrier was studied by He et al. [20]. Herein, it can be deduced that no publications are found concerning the simultaneous removal of cobalt cationic species $\left(\mathrm{Co}^{2+}\right)$ and manganese anionic species $\left(\mathrm{MnO}_{4}{ }^{-}\right)$, which is the objective of the present investigation.

In this research, polyacrylonitrile/hexadecyltrimethylammonium bromide/potassium copper hexacyanoferrate (III), PAN/HDTMA/KCuHCF, composite was synthesized and characterized for removal of radiocobalt cations $\left({ }^{60} \mathrm{Co}^{2+}\right)$ and manganese anion $\left(\mathrm{MnO}_{4}^{-}\right)$from their binary aqueous solutions. To achieve this goal, the effect of many variables such as $\mathrm{pH}$, contact time, adsorbate concentration, adsorbent mass and temperature on simultaneous adsorption process of the concerned species was evaluated. Besides, various kinetic and isotherm mathematical models were used to analyze the kinetic and equilibrium isotherm data, respectively, and the thermodynamic parameters were estimated.

\section{Materials and methods}

\subsection{Materials}

Cobalt chloride $\left(\mathrm{CoCl}_{2} \cdot 6 \mathrm{H}_{2} \mathrm{O}\right)$ was purchased from Fluka. The radioactive ${ }^{60} \mathrm{Co}^{2+}$ was obtained by irradiation of cobalt chloride hexahydrate in the Egypt Second Research Reactor and was used as a radiotracer during conducting the adsorption experiments of the present work. Potassium permanganate $\left(\mathrm{KMnO}_{4}\right)$ was purchased from
Sigma-Aldrich. Acrylonitrile (AN, 99\% purity) was obtained from Cambrian Chemicals. Potassium persulfate (KPS, $\mathrm{K}_{2} \mathrm{~S}_{2} \mathrm{O}_{8}$ ) and hexadecyltrimethylammonium bromide cationic surfactant (purity >98\%) were supplied by Merck. Potassium hexacyanoferrate (III) (KHFC, $\left.\mathrm{K}_{3}\left[\mathrm{Fe}(\mathrm{CN})_{6}\right] \cdot 3 \mathrm{H}_{2} \mathrm{O}\right)$, copper chloride $\left(\mathrm{CuCl}_{2} \cdot 2 \mathrm{H}_{2} \mathrm{O}\right)$, ammonium sulfate $\left(\left(\mathrm{NH}_{4}\right)_{2} \mathrm{SO}_{4}\right)$, aluminum nitrate $\left(\mathrm{Al}\left(\mathrm{NO}_{3}\right)_{3} \cdot 9 \mathrm{H}_{2} \mathrm{O}\right)$ were obtained by Riedel-de-Haen. Sodium hydroxide $(\mathrm{NaOH})$ and hydrochloric acid $(\mathrm{HCl})$ were purchased from Chem-Lab.

\subsection{Synthesis of PAN/HDTMA/KCuHCF composite}

PAN/HDTMA/KCuHCF was synthesized according to the schematic representation shown in Figure 1. In a beaker, hexadecyltrimethylammonium bromide, HDTMA, solution $(0.72 \mathrm{~g} / 40 \mathrm{~mL}$ distilled water) was mixed with $20 \mathrm{~mL}$ AN. This mixture was kept at $60{ }^{\circ} \mathrm{C}$ under magnetic stirring at $120 \mathrm{rpm}$ for $10 \mathrm{~min}$. Then $50 \mathrm{~mL}$ of $0.5 \mathrm{M}$ copper chloride solution was added to this mixture followed by the addition of $30 \mathrm{~mL}$ distilled water (DW) containing $1 \mathrm{~g}$ KPS. The stirring was continued until the beginning of the polymerization process which was visually observed via the formation of white particles. Potassium hexacyanoferrate(III), KHCF, solution (150 mL, 0.5M) was then added drop-wise. The formed PAN/HDTMA/KCuHCF suspension was aged at $60{ }^{\circ} \mathrm{C}$ under stirring for $2 \mathrm{~h}$. Afterward, the solid particles were allowed to settle and the liquid phase was removed by decantation. The remained solid phase was washed several times with distilled water. The collected solid particles were eventually transferred to a Petri dish and dried at $80^{\circ} \mathrm{C}$ for $24 \mathrm{~h}$ and ground into fine particles. Polyacrylonitrile (PAN) particles were also synthesized according to the procedures illustrated in Figure 1 but in absence of HDTMA, KHCF and copper chloride solutions. Whereas, particles of potassium copper hexacyanoferrate (KCuHCF) were synthesized in absence of AN, HDTMA and KPS.

\subsection{Measurements}

For qualitative analysis of the surface functional groups of polyacrylonitrile (PAN), potassium copper hexacyanoferrate (KCuHCF) and the concerned composite (PAN/HDTMA/KCuHCF), the materials were characterized by Fourier transform infrared spectroscopy (FT-IR) using a Nicolet is 10 spectrometer (USA) in the range $4000-400 \mathrm{~cm}^{-1}$ with $4 \mathrm{~cm}^{-1}$ resolution using $\mathrm{KBr}$ method. X-ray diffraction patterns of PAN, KCuHCF and PAN/HDTMA/KCuHCF were recorded using a Philips PW1830 diffractometer with $\mathrm{Cu} \mathrm{K} \alpha$ as the incident radiation. The thermal stability of the materials was evaluated using a Shimadzu DTA-TG50 thermal analyzer (Japan). Thermogravimetric analysis (TGA) was performed in the temperature range of $50-700{ }^{\circ} \mathrm{C}$ at a heating rate of $20{ }^{\circ} \mathrm{C} / \mathrm{min}$. The radioactivity of ${ }^{60} \mathrm{Co}^{2+}$ radionuclides before and after adsorption experiments was measured radiometrically using a NaI scintillation counter connected to single channel spectrometer (Spectech ST 360 to crystal, USA). While, the concentration of manganese was determined spectrophotometrically using a Spectronic-20 Uv-Vis spectrophotometer (USA). Batch adsorption experiments were conducted in a temperature controlled water bath orbital shaker (Stuart SBS40, UK). A Heidolph magnetic stirrer (MR 3001 type, Germany) was used for stirring purposes during synthesis process of the materials. After adsorption experiments, the solid phase was separated by centrifugation using a Chirana centrifuge (Germany). A HANNA pH-meter (model HI 8519, Italy) was used for adjustment of the solution $\mathrm{pH}$. 


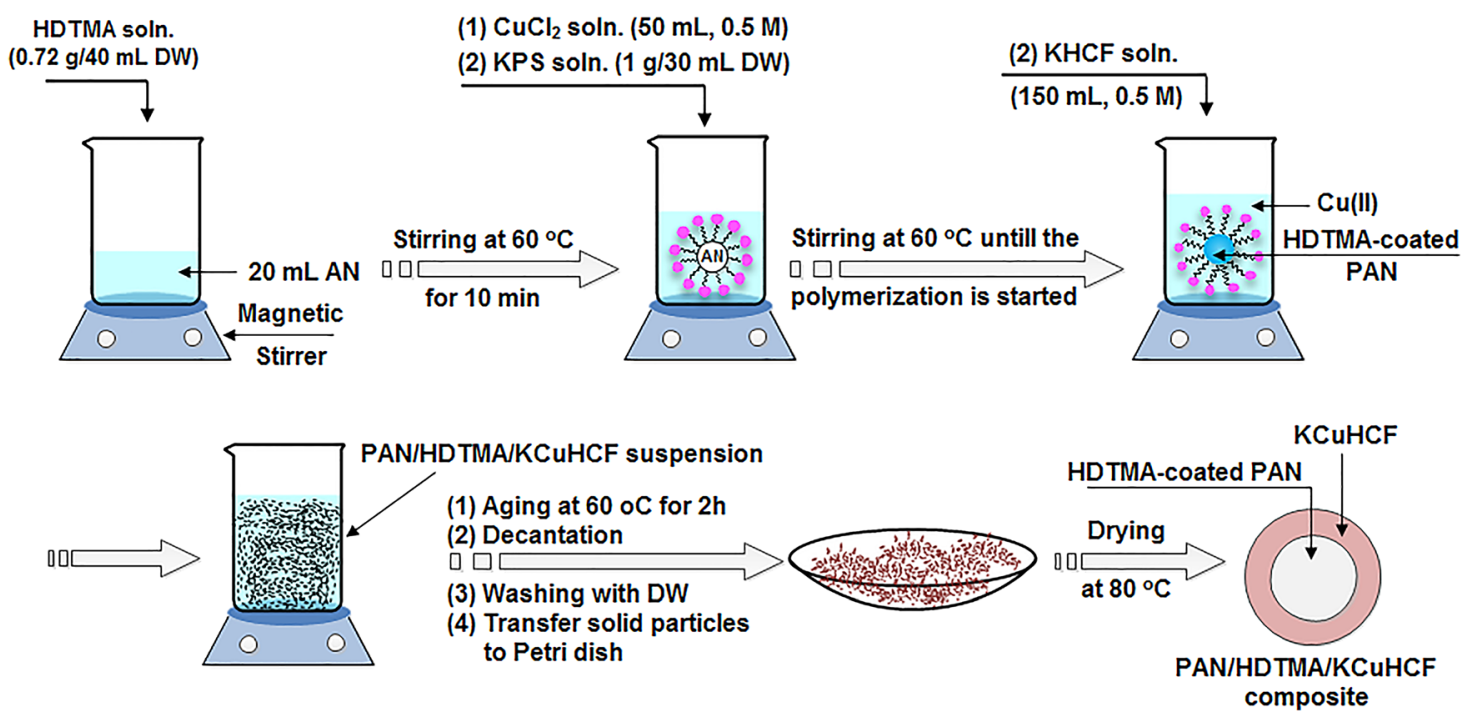

Figure 1: Synthesis scheme of PAN/HDTMA/KCUHCF composite.

\subsection{Adsorption experiments of cobalt and manganese}

The influence of the solution $\mathrm{pH}$ at PAN/HDTMA/KCuHCF masses of 1 and $4 \mathrm{~g} / \mathrm{L}$ was studied in the $\mathrm{pH}$ range $1.5-7.7$ by adding the required adsorbent mass to $5 \mathrm{~mL}$ adsorbate solution, containing $30 \mathrm{mg} / \mathrm{L}$ cobalt (spiked with ${ }^{60} \mathrm{Co}$ ) and $137 \mathrm{mg} / \mathrm{L}$ manganese, adjusted to the desired $\mathrm{pH}$. The suspensions were then shaked using an orbital water bath shaker at a shaking speed of $120 \mathrm{rpm}$ for $2 \mathrm{~h}$. The solid phase was then separated by centrifugation at $4000 \mathrm{rpm}$ and the radioactivity of ${ }^{60} \mathrm{Co}$ and the concentration of manganese in the liquid phase were measured radiometrically and spectrophotometrically, respectively. Adsorption experiments of $30 \mathrm{mg} / \mathrm{L}$ cobalt and $137 \mathrm{mg} / \mathrm{L}$ manganese at PAN/HDTMA/KCuHCF masses in the range 1-4 g/L were performed by contacting the adsorbent with $5 \mathrm{~mL}$ adsorbate solution of $\mathrm{pH} 3.5$. The stirring speed and the reaction time were kept constant at $120 \mathrm{rpm}$ and $2 \mathrm{~h}$, respectively. After equilibration, the contents of the glass bottles were centrifuged the aqueous phase was radiometrically (in case of ${ }^{60} \mathrm{Co}$ ) and spectrophotometrically (in case of manganese) analyzed. Kinetic studies of the present adsorption processes at different adsorbate concentration were studied by adding $4 \mathrm{~g} / \mathrm{L}$ PAN/HDTMA/ $\mathrm{KCuHCF}$ to $5 \mathrm{~mL}$ adsorbate solution ( 30 and $60 \mathrm{mg} / \mathrm{L}$ cobalt and 55 and $137 \mathrm{mg} / \mathrm{L}$ manganese). The $\mathrm{pH}$ of the solution was maintained constant at 3.5 using negligible volumes of $\mathrm{HCl}$ or $\mathrm{NaOH}$ solutions while the shaking speed was fixed at $120 \mathrm{rpm}$. At pre-determined time intervals, samples were withdrawn and centrifuged at $4000 \mathrm{rpm}$ and the radioactivity of ${ }^{60} \mathrm{Co}$ as well as the concentration of manganese in the liquid phase was determined. The effect of temperature on adsorption processes of cobalt and manganese was investigated at 25, 35, 45 and $60{ }^{\circ} \mathrm{C}$ using $4 \mathrm{~g} / \mathrm{L}$ PAN/HDTMA/KCuHCF composite at $\mathrm{pH}$ 3.5. The adsorbate and adsorbent suspension was equilibrated for $2 \mathrm{~h}$ at $120 \mathrm{rpm}$. The impact of the initial concentrations of cobalt and manganese on their adsorption efficiency was studied by adding $4 \mathrm{~g} / \mathrm{L}$ PAN/HDTMA/KCuHCF to the adsorbate solution of the required initial concentration adjusted at $\mathrm{pH} 3.3$ and the suspensions were equilibrated for $2 \mathrm{~h}$. The suspensions were then centrifuged at $4000 \mathrm{rpm}$ for determination of ${ }^{60} \mathrm{Co}$ radioactivity and manganese concentration in the supernatant.

\subsection{Data presentation}

Adsorption data of cobalt and manganese were represented as removal \%, adsorbed amount of adsorbate $(Q)$ and distribution coefficient $\left(K_{d}\right)$ which were calculated using the following relations:

$$
\begin{gathered}
\text { Removal \% of radiocobalt }=\frac{A_{\text {initial }}-A_{\text {final }}}{A_{\text {initial }}} \times 100 \\
\text { Removal } \% \text { of manganese }=\frac{[C]_{\text {initial }}-[C]_{\text {final }}}{[C]_{\text {initial }}} \times 100 \\
Q(m g / g)=\frac{\text { Removal } \%}{100} \times C_{\text {initial }} \times \frac{V}{W} \\
K_{d}(m L / g)_{\text {radiocobalt }}=\frac{A_{\text {initial }}-A_{\text {final }}}{A_{\text {final }}} \times \frac{V}{W} \\
K_{d}(L / g)_{\text {manganese }}=\frac{[C]_{\text {initial }}-[C]_{\text {final }}}{[C]_{\text {final }}} \times \frac{V}{W}
\end{gathered}
$$

where $A$ is the radioactivity of ${ }^{60} \mathrm{Co}, C$ is the initial concentration of adsorbate $(\mathrm{mg} / \mathrm{L}), V$ is the volume of the adsorbate solution (L) and $W$ is the mass of PAN/HDTMA/KCuHCF composite $(\mathrm{g})$.

\subsection{Desorption studies}

various desorbing agents $\left(\left(\mathrm{NH}_{4}\right)_{2} \mathrm{SO}_{4}, \mathrm{CaCl}_{2}, \mathrm{Al}\left(\mathrm{NO}_{3}\right)_{3}, \mathrm{HCl}\right.$ and $\mathrm{Na}_{2} \mathrm{HPO}_{4}$ ) in the concentration range $0.001-0.1 \mathrm{~mol} / \mathrm{L}$ were used to evaluate the desorption processes of cobalt and manganese ions loaded onto PAN/HDTMA/KCuHCF at the optimum adsorption conditions ([cobalt] $=30 \mathrm{mg} / \mathrm{L}$, [manganese] $=137 \mathrm{mg} / \mathrm{L}$, PAN/HDTMA/ $\mathrm{KCuHCF}$ mass $=4 \mathrm{~g} / \mathrm{L}, \mathrm{pH}=3.3$, stirring time $=2 \mathrm{~h}$, stirring speed $=120 \mathrm{rpm}$ ). Desorption experiments were conducted by adding $5 \mathrm{~mL}$ desorbing agent of the required concentration to PAN/HDTMA/ KCuHCF particles loaded with cobalt and manganese. The suspensions were kept under stirring for $24 \mathrm{~h}$ at $120 \mathrm{rpm}$. And then were centrifuged at $4000 \mathrm{rpm}$. The radioactivity of ${ }^{60} \mathrm{Co}$ and the concentration of manganese in the supernatant, obtained by centrifugation of the suspensions at $4000 \mathrm{rpm}$, were determined. The desorption percentage (desorption\%) of the studied adsorbates was calculated as follow: 


$$
\begin{gathered}
\text { Desorption \% of radiocobalt }=\frac{A_{\text {dsorbed }} \times V_{d}}{\left(A_{\text {initial }}-A_{\text {final }}\right) \times V} \times 100 \\
\text { Desorption \% of manganese }=\frac{[C]_{\text {desorbed }} \times V_{d}}{\left([C]_{\text {initial }}-[C]_{\text {final }}\right) \times V} \times 100
\end{gathered}
$$

Where $C$ is the concentration of manganese, $V_{d}$ is volume of desorption solution (L), $A$ and $V$ are previously defined.

\section{Results and discussion}

\subsection{Characterization}

The FT-IR spectra of PAN, KCuHFC and PAN/HDTMA/ KCuHCF are shown in Figure 2A. This figure demonstrates that these materials exhibited various absorption peaks due to the existence of different functional groups. The broad absorption peaks around $3442 \mathrm{~cm}^{-1}$ observed in the spectra of the characterized materials are attributed to the stretching vibration of $\mathrm{OH}$ groups of interstitial water. The absorption peaks at 2924 and $2865 \mathrm{~cm}^{-1}$ for PAN/HDTMA/ $\mathrm{KCuHCF}$ spectra are ascribed to the stretching vibration of $\mathrm{C}-\mathrm{H}$. These peaks together with that at $1410 \mathrm{~cm}^{-1}$ (due to the stretching vibration of $\mathrm{C}-\mathrm{N}$ ) confirmed the occurrence of HDTMA in the synthesized composite. The sharp and intense peaks at $2098 \mathrm{~cm}^{-1}$ (for KCuHCF) and $2248 \mathrm{~cm}^{-1}$ (for PAN) are attributed to the stretching vibration of nitrile $(\mathrm{C} \equiv \mathrm{N})$ group. These absorption peaks are also coexisted in the spectrum of PAN/HDTMA/KCuHCF. The absorption peaks located at $1615 \mathrm{~cm}^{-1}$ in the spectra of PAN, KCuHFC and PAN/HDTMA/KCuHCF are attributed to the bending vibration of interstitial water molecules. The absorption peaks at $1426 \mathrm{~cm}^{-1}$ in the spectra of PAN and PAN/HDTMA/ KCuHCF are assigned to the bending vibration of $\mathrm{CH}_{2}$ group. The absorption peaks observed at 485 and $496 \mathrm{~cm}^{-1}$ in the spectra of PAN and PAN/HDTMA/KCuHCF composite indicated the occurrence of metal-carbon bond. Regarding the spectra shown in Figure 2A, it can be seen that the absorption peaks of PAN and $\mathrm{KCuFC}$ are coexisted in that of PAN/HDTMA/KCuHCF, which indicated the formation of the concerned composite.

To evaluate the thermal stability of PAN/HDTMA/ KCuHCF composite, the TGA were conducted in the temperature range $50-700{ }^{\circ} \mathrm{C}$ and compared with those of PAN and $\mathrm{KCuHCF}$. The obtained data are depicted in Figure 2B. Regarding the thermogram of PAN, it can be noted that there is no weight loss is recorded up to $300{ }^{\circ} \mathrm{C}$, whereas a sharp weight loss is observed in the temperature range $300-340{ }^{\circ} \mathrm{C}$ that followed by a gradual decrease in PAN weight with increasing temperature and finally reached to $84 \%$ at $700^{\circ} \mathrm{C}$. For KCuHFC and PAN/HDTMA/KCuHCF, the weight loss (35.5 and $24.7 \%$, respectively) at $200{ }^{\circ} \mathrm{C}$ is ascribed to the release of free and interstitial water molecules [21]. Further temperature increase, increased the weight loss of $\mathrm{KCuHFC}$ and weight loss of $51 \%$ is observed at $388{ }^{\circ} \mathrm{C}$ which remained unchanged up to $700{ }^{\circ} \mathrm{C}$. The weight loss in the temperature range $200-350^{\circ} \mathrm{C}$ for PAN/ HDTMA/KCuHCF can be attributed to the decomposition of the surfactant hexadecyltrimethylammonium bromide [13]. The weight loss observed for PAN/HDTMA/KCuHCF composite at temperature $>350{ }^{\circ} \mathrm{C}$ is attributed to:
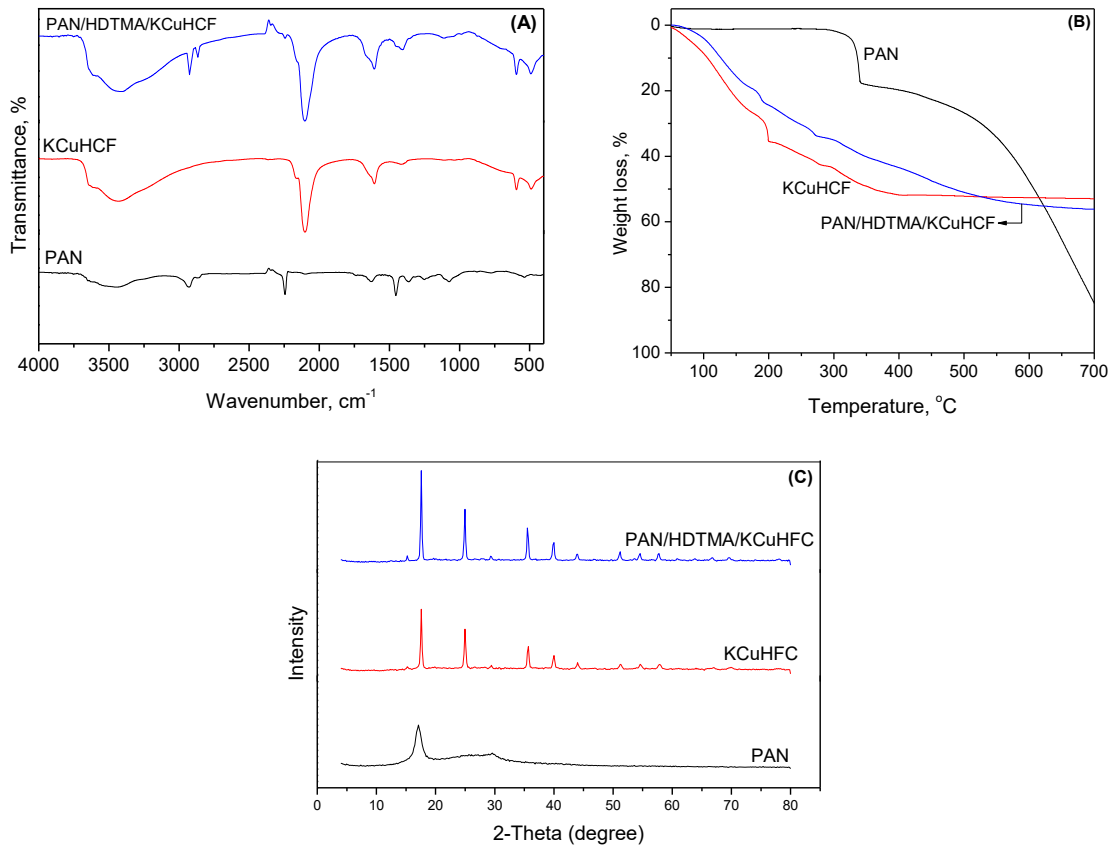

Figure 2: FT-IR (A), TGA (B) and XRD (C) of PAN/HDTMA/KCUHCF composite. 
(i) decomposition of KCuHFC to copper and iron oxides [13] and (ii) decomposition of PAN with the release of hydrogen cyanide and ammonia gasses [21, 22].

The XRD patterns of PAN, KCuHFC and PAN/HDTMA/ $\mathrm{KCuHCF}$ are shown in Figure $2 \mathrm{C}$. The two diffraction peaks observed at $2 \theta$ of $17.1^{\circ}$ and $29.8^{\circ}$ for PAN indicates its crystalline structure. This obtained XRD pattern of PAN agrees well with those reported in literature [13-25]. The XRD pattern of KCuHFC showed diffraction peaks at $2 \theta$ of $17.5^{\circ}, 24.9^{\circ}, 35.8^{\circ}, 39.9^{\circ}, 43.9^{\circ}, 51.3^{\circ}, 54.7^{\circ}$ and $57.8^{\circ}$, which are characteristic peaks for crystalline metal ferrocyanides $[26,27]$. The coexistence of PAN and KCuFC diffraction peaks at the XRD pattern of PAN/HDTMA/KCuHCF confirmed the occurrence of their particles in the synthesized composite.

\subsection{Effect of the solution $\mathrm{pH}$}

The effect of the solution $\mathrm{pH}$ on the removal percentage of cobalt and manganese is studied at PAN/HDTMA/KCuHCF composite dosages of 1 and $4 \mathrm{~g} / \mathrm{L}$. The data obtained are depicted in Figure 3A. At the studied adsorbent dosages, the data given in this figure show that the removal percentage of cobalt is abruptly increased with increasing the $\mathrm{pH}$ of the solution and almost complete removals are attained at $\mathrm{pH}$ values $\geq 3.3$. For manganese ion, removal percentage of about $76 \%$ are achieved below pH 3.3 using
$1 \mathrm{~g} / \mathrm{L}$ PAN/HDTMA/KCuHCF composite. Beyond this value, the removal percentage is decreased with increasing the solution $\mathrm{pH}$ and reached to about $56 \%$ at $\mathrm{pH} 7.8$. By increasing the adsorbent dosage to $4 \mathrm{~g} / \mathrm{L}$, removal percentage more than $99.5 \%$ are achieved for manganese at the studied $\mathrm{pH}$ range of 1.5-7.8.

The data depicted in Figure 3A could be interpreted by taking into consideration the speciation diagram of cobalt(II) and manganese(VII) demonstrated in Figure 3B, which are calculated using the Phreeqc software. As shown by this figure, $\mathrm{Co}^{2+}$ ion is the predominant species of cobalt(II) at $\mathrm{pH}$ values below 6 . Further increase in the solution $\mathrm{pH}$ resulted into the formation of $\mathrm{Co}(\mathrm{OH})_{2}$ insoluble species which became the predominant one at $\mathrm{pH}>8$. On the other hand, $\mathrm{MnO}_{4}{ }^{-}$anion is the dominant species of manganese(VII) in the $\mathrm{pH}$ range $1-13$. This implies that cobalt is adsorbed onto PAN/HDTMA/KCuHCF at $\mathrm{pH}$ below 6 via ion exchange of $\mathrm{Co}^{2+}$ cations with $\mathrm{K}^{+}$and/or $\mathrm{Cu}^{2+}$ ions at the adsorbent surface. Beside this adsorption mechanism, precipitation of cobalt as $\mathrm{Co}(\mathrm{OH})_{2}$ participated in the removals achieved for cobalt at $\mathrm{pH}$ values higher than 6 . The reduction in the removal percentage of cobalt at $\mathrm{pH}$ values $<3$ is attributed to the competition between $\mathrm{H}^{+}$and $\mathrm{Co}^{2+}$ ions for adsorption onto the employed adsorbent. Ion exchange of $\mathrm{MnO}_{4}^{-}$with the surfactant (HDTMA) counter anion $\left(\mathrm{Br}^{-}\right)$at the composite is considered the main reason for adsorption of manganese onto PAN/HDTMA/KCuHCF. It is reported that the positive charge of the quaternary
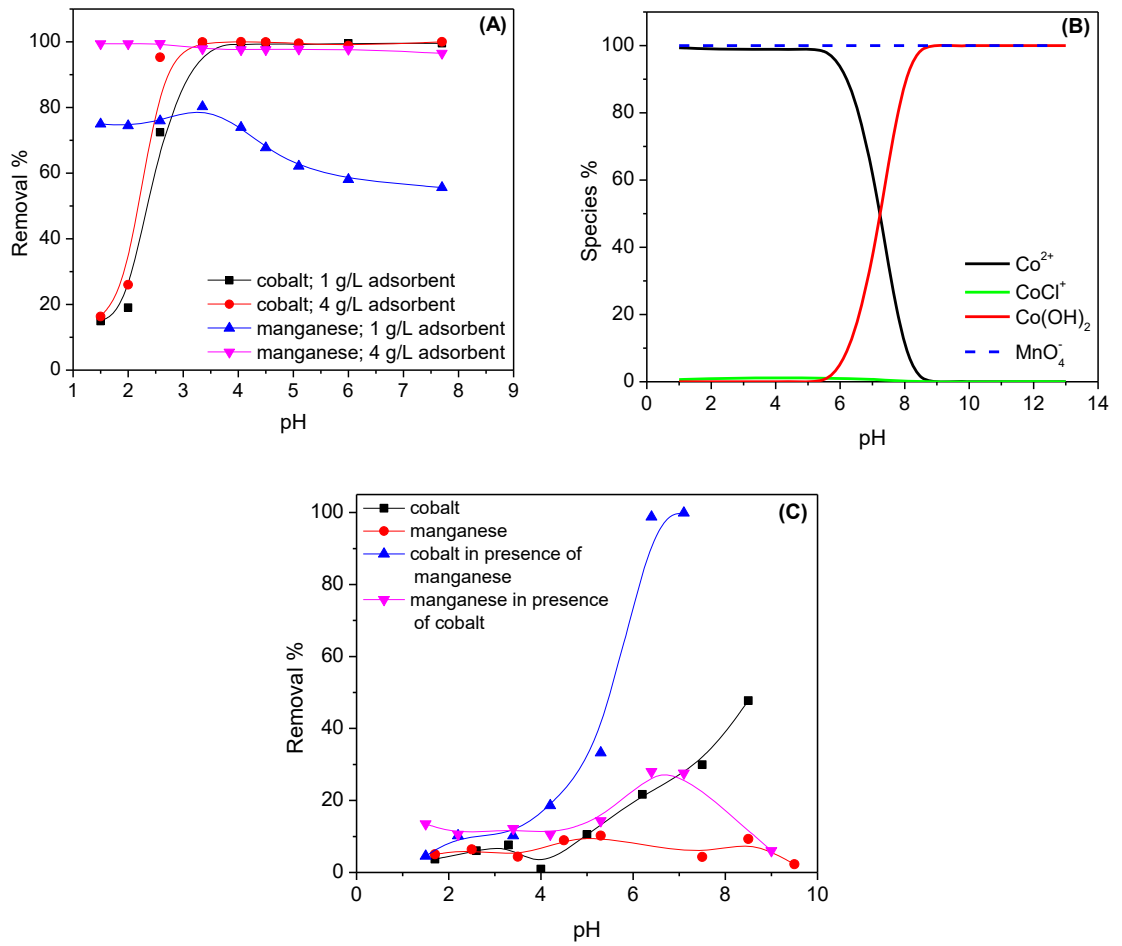

Figure 3: Effect of the solution $\mathrm{pH}$ on the removal percentage $(A)$, speciation $(B)$ and precipitation $(C)$ of cobalt and manganese. 
ammonium surfactants, HDTMA among them, is unaffected by the solution $\mathrm{pH}$ [28]. Therefore, changing the solution $\mathrm{pH}$ is found to have no effect on the removal percentage of manganese at $4 \mathrm{~g} / \mathrm{L}$ PAN/HDTMA/KCuHCF composite (Figure 3A).

Figure $3 \mathrm{C}$ illustrates the effect of the solution $\mathrm{pH}$ on the removal percentage of cobalt and manganese in absence of the adsorbent. In absence of manganese, removal percentages less than $10 \%$ are obtained for cobalt at $\mathrm{pH}$ values $\leq 4$. By increasing the solution $\mathrm{pH}$, the removal percentage is increased which reached to $47.6 \%$ at $\mathrm{pH} 8.5$. This increment in the removal percentage is attributed to precipitation of cobalt as $\mathrm{Co}(\mathrm{OH})_{2}$. On the other hand, the removal percentage of cobalt is sharply increased at $\mathrm{pH} \geq 3.5$ in presence of manganese and almost complete removals are attained at $\mathrm{pH} \geq 6.4$. The shift in the precipitation $\mathrm{pH}$ to a lower value and the high precipitation percentages obtained for cobalt is presumably attributed to oxidation of cobalt(II) to cobalt(III) by manganese(VII) and the subsequent formation of $\mathrm{Co}(\mathrm{OH})_{3}$ precipitate. Oxidation of cobalt(II) to cobalt(III) by manganese(VII) has been previously reported in literature [29]. The speciation data of manganese(VII) depicted in Figure 3B show that $\mathrm{MnO}_{4}{ }^{-}$is the predominant species of manganese in the $\mathrm{pH}$ range 1-13. However, about $28 \%$ of manganese is removed in presence of cobalt in the pH range 6.2-7.1 without utilization of the adsorbent. This finding can be ascribed to coprecipitation and/or adsorption of $\mathrm{MnO}_{4}{ }^{-}$by cobalt hydroxide precipitate. Based on the results of the effect of the solution $\mathrm{pH}$ on removal percentage of cobalt and manganese in absence of the adsorbent (Figure 3C) and the data given in Figure 3A, the subsequent adsorption experiments were conducted at $\mathrm{pH} 3.5$ to avoid precipitation of cobalt.

\subsection{Effect of PAN/HDTMA/KCuHCF dosage}

The influence of the adsorbent dosage on the removal percentages and the adsorbed amounts of cobalt and manganese are shown in Figure 4. This figure clarifies that both the removal percentage and the adsorbed amount of the concerned toxicants are markedly dependent on the adsorbent dosage. By increasing the dosage of PAN/ HDTMA/KCuHCF, the removal percentage is increased and reached to its maximum value of about $99 \%$ at 1.5 and $3 \mathrm{~g} / \mathrm{L}$ for cobalt and manganese, respectively. On the other hand, increasing the adsorbent dosage from 1 to $4 \mathrm{~g} / \mathrm{L}$ decreased the adsorbed amount from 99.3 to $39.1 \mathrm{mg} / \mathrm{g}$ for manganese and from 27.8 to $7.9 \mathrm{mg} / \mathrm{g}$ for cobalt. The increase in the number of functional groups at the surface of PAN/ HDTMA/KCuHCF composite with increasing the adsorbent dosage is considered the reason for increasing the removal percentage of cobalt and manganese shown in Figure 4 [30]. On the other hand, the reduction in the adsorbed amount could be mathematically explained. Regarding the mathematical relation used for calculating values of the adsorbed amount of the concerned ions (Eq. (3)), it can be observed that this value is directly proportional to the removal percentage while inversely proportional to the amount of adsorbate $(W)$. Although the removal percentage of adsorbates is increased with increasing the amount of PAN/HDTMA/KCuHCF composite, this increase was low compared to the increase in the value of $W$. Thus, the adsorbed amount of the adsorbates is negatively affected by the increase in the value of $W$. Since the main objective of this investigation was to simultaneously remove cobalt and manganese from aqueous solutions, an adsorbent dosage of $4 \mathrm{~g} / \mathrm{L}$ was therefore the most adequate one (Figure 4).

\subsection{Kinetic studies}

The effect of contact time on the removal percentage of cobalt and manganese is studied at different initial adsorbate concentrations using adsorbent dosage of $4 \mathrm{~g} / \mathrm{L}$ at $\mathrm{pH} 3.5$ (Figure 5) demonstrates that the removal percentages of the studied toxicants are sharply increased in the beginning of the adsorption process and almost complete removals are achieved for cobalt at the studied concentrations in the first minute. While most of manganese ions, $70 \%$, are uptaken by PAN/HDTMA/KCuHCF composite in the first minute. Then, a gradual increase in its removal percentage is observed with time and maximum

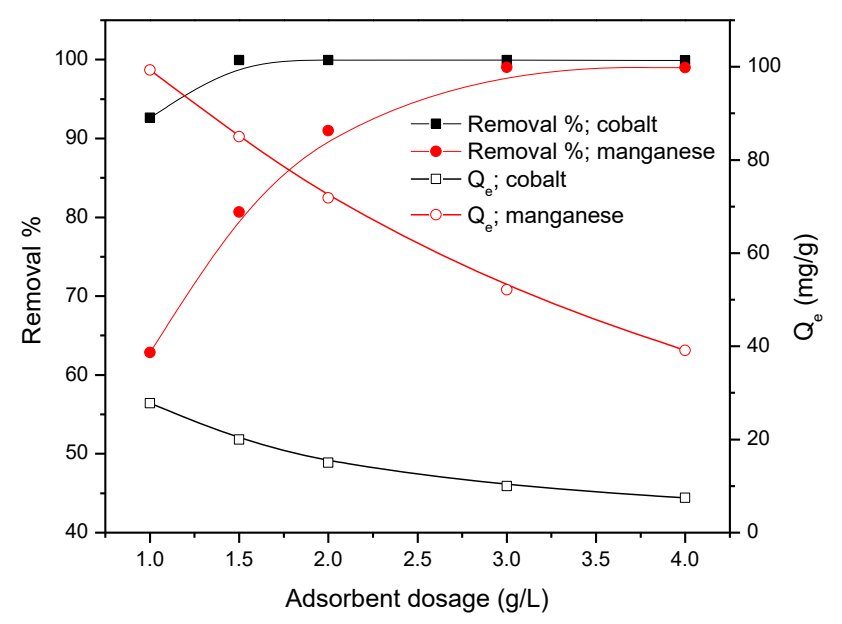

Figure 4: Effect of PAN/HDTMA/KCuHCF dosage on the removal percentage and the adsorbed amounts of cobalt and manganese. 


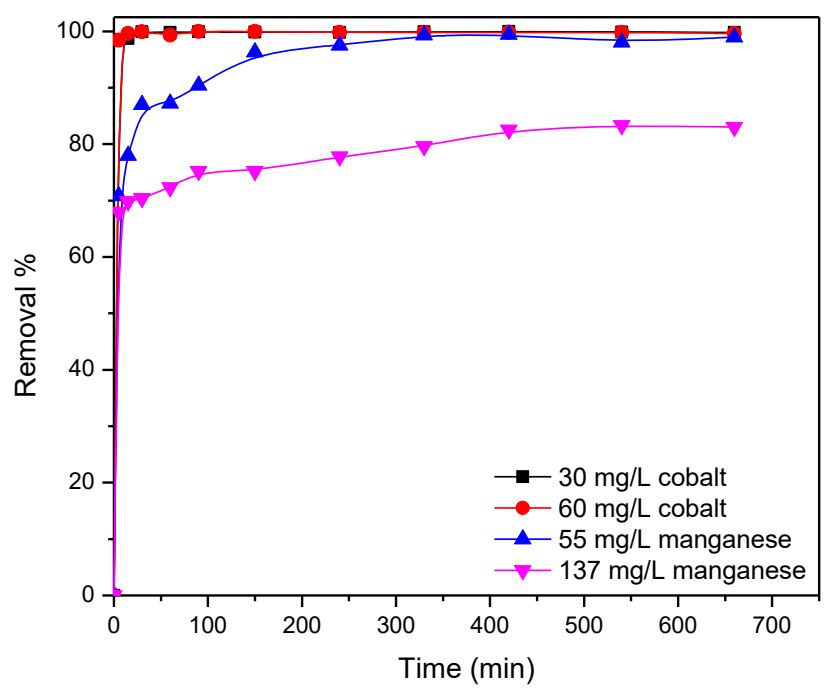

Figure 5: Adsorption kinetics of cobalt and manganese at different concentrations on PAN/HDTMA/KCUHCF composite.

removals of about $99 \%$ (at $55 \mathrm{mg} / \mathrm{L}$ ) and $80 \%$ (at $137 \mathrm{mg} / \mathrm{L}$ ) are obtained at 330 and $410 \mathrm{~min}$, respectively. For designing an effective adsorption process, determination of the kinetic parameters is essential. The kinetic data given in Figure 5 revealed that the equilibrium for adsorption of cobalt onto PAN/HDTMA/KCuHCF composite is attained in the beginning of the adsorption process. Such data could not be modeled to adsorption kinetic models. Consequently, only the adsorption kinetic data of manganese are analyzed by three extensively applied kinetic models. These models are the Lagergren-first-order (Eq. (8)), the Pseudo-second-order (Eq. (9)) and the Elovich (Eq. (10)), which are expressed by the following equations $[12,31,32]:$

$$
\begin{gathered}
\log \left(Q_{e}-Q_{t}\right)=\log Q_{e 1}-\left(\frac{K_{1}}{2.303}\right) t \\
\frac{t}{Q_{t}}=\frac{1}{K_{2} Q_{e 2}^{2}}+\left(\frac{1}{Q_{e 2}}\right) t \\
Q_{t}=\frac{1}{\beta} \ln (\alpha \beta)+\left(\frac{1}{\beta}\right) \ln t
\end{gathered}
$$

where $Q_{\mathrm{e}}$ and $Q_{\mathrm{t}}$ are the adsorbed amount of manganese $(\mathrm{mg} / \mathrm{g})$ at equilibrium and at time $t$, respectively. The kinetic parameters, $K_{1}\left(\mathrm{~min}^{-1}\right)$ and $Q_{\mathrm{e} 1}(\mathrm{mg} / \mathrm{g})$ for the Lagergrenfirst-order, $Q_{\mathrm{e} 2}(\mathrm{mg} / \mathrm{g})$ and $K_{2}(\mathrm{~g} / \mathrm{mg} \mathrm{min})$ for the pseudosecond-order along with $\beta(\mathrm{g} / \mathrm{mg})$ and $\alpha(\mathrm{mg} / \mathrm{g} \mathrm{min})$ for the Elovich model are estimated from the slop and intercept of linear plots of $\log \left(Q_{\mathrm{e}}-Q_{\mathrm{t}}\right)$ versus $t, t / Q_{\mathrm{t}}$ versus $t$ and $Q_{\mathrm{t}}$ versus lnt, respectively. Linear fittings of adsorption kinetic data of manganese onto PAN/HDTMA/KCuHCF composite to the aforementioned kinetic models are given in Figure 6 and the calculated kinetic parameters are tabulated in Table 1. Figure 6 indicates that good linear plots are observed at the studied manganese concentrations. But shedding more light on the correlation coefficient $\left(R^{2}\right)$ values for each plot recorded in Table 1, it can be obviously seen that the pseudo-second-order kinetic model exhibited higher values
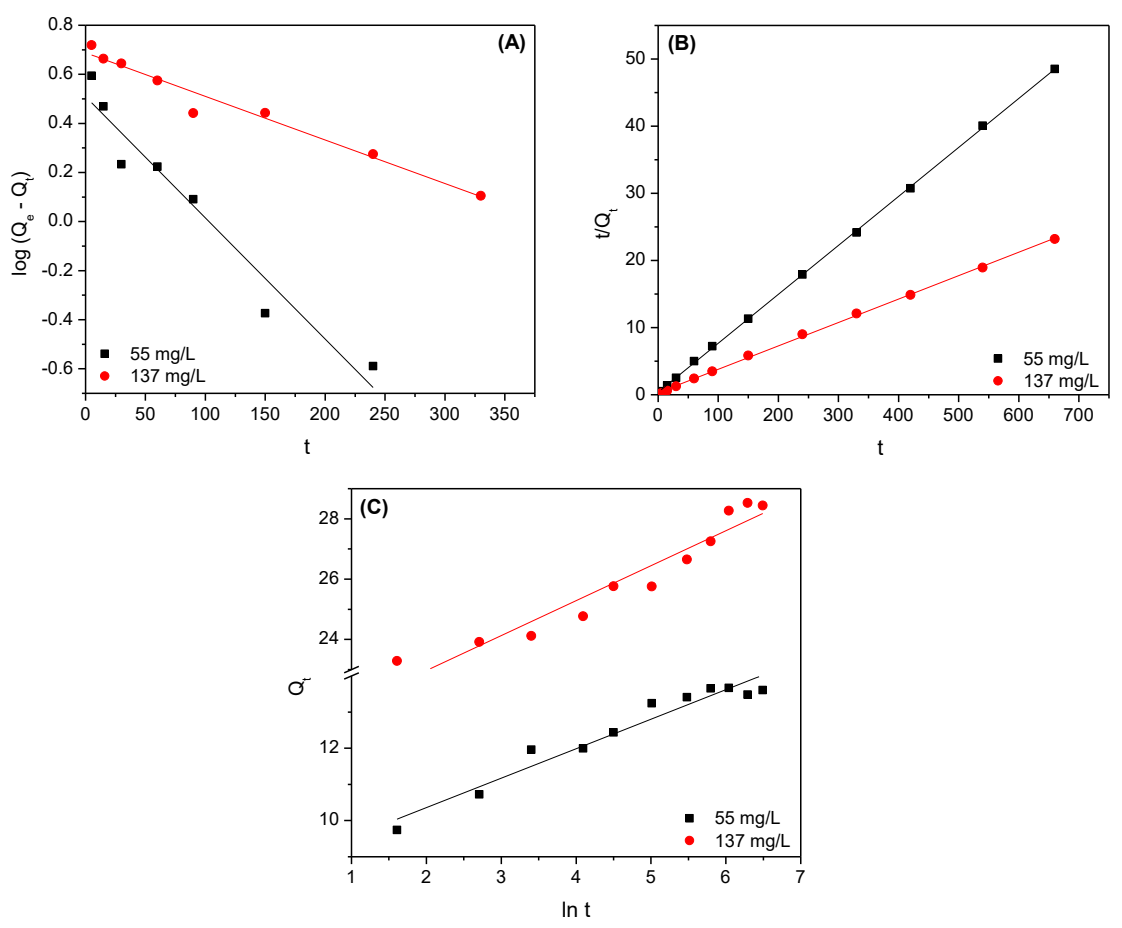

Figure 6: Pseudo-first-order (A), pseudosecond-order (B) and Elovich (C) plots for adsorption of 55 and $137 \mathrm{mg} / \mathrm{L}$ manganese onto PAN/HDTMA/KCUHCF composite. 
Table 1: Kinetic parameters for adsorption of manganese onto PAN/ HDTMA/KCUHCF composite.

\begin{tabular}{|c|c|c|c|}
\hline Kinetic model & Parameter & $55 \mathrm{mg} / \mathrm{L}$ & $137 \mathrm{mg} / \mathrm{L}$ \\
\hline \multirow[t]{3}{*}{ Lagergren-first-order } & $k_{1}\left(\min ^{-1}\right)$ & 0.011 & 0.004 \\
\hline & $Q_{\mathrm{e} 1}(\mathrm{mg} / \mathrm{g})$ & 3.228 & 4.871 \\
\hline & $R^{2}$ & 0.937 & 0.963 \\
\hline \multirow[t]{3}{*}{ Pseudo-second-order } & $k_{2}(\mathrm{~g} / \mathrm{mg} \min )$ & 69.647 & 254.513 \\
\hline & $Q_{\mathrm{e} 2}(\mathrm{mg} / \mathrm{g})$ & 13.709 & 28.694 \\
\hline & $R^{2}$ & 0.999 & 0.999 \\
\hline \multirow[t]{3}{*}{ Elovich } & $\alpha(\mathrm{mg} / \mathrm{g} \min )$ & $3.6 \mathrm{E} 4$ & $6.4 \mathrm{E} 6$ \\
\hline & $\beta(g / m g)$ & 1.227 & 0.863 \\
\hline & $R^{2}$ & 0.941 & 0.918 \\
\hline \multirow[t]{3}{*}{ Weber-Morris } & 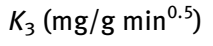 & 0.321 & 0.255 \\
\hline & $C$ & 9.483 & 22.836 \\
\hline & $R^{2}$ & 0.951 & 0.989 \\
\hline \multirow[t]{2}{*}{ Boyd } & Intercept & 0.694 & 1.131 \\
\hline & $R^{2}$ & 0.919 & 0.877 \\
\hline
\end{tabular}

$\left(R^{2}=0.999\right.$ for the studied concentrations) than the Lagergren-first-order $\left(R^{2}=0.937\right.$ and 0.963$)$ and the Elovich model $\left(R^{2}=0.941\right.$ and 0.918$)$ for 55 and $137 \mathrm{mg} / \mathrm{L}$ manganese, respectively. This finding suggested that the pseudosecond-order kinetic model was the best one for describing the adsorption kinetic data of manganese onto the employed adsorbent. Increasing the pseudo-second-order rate constant from 69.647 to $254.513 \mathrm{~g} / \mathrm{mg} \mathrm{min}$ with increasing the initial adsorbate concentration from 55 to $137 \mathrm{mg} / \mathrm{L}$ can be attributed to the increase of the adsorbed amount from 13.709 to $28.694 \mathrm{mg} / \mathrm{g}$.

It is well-known that the uptake of an adsorbate by an adsorbent involves [33]: (i) transport of adsorbate from bulk solution to the adsorbent surface (bulk diffusion), (ii) diffusion of the adsorbate through the boundary layer to the external surface of the adsorbent (film diffusion), (iii) transport of the adsorbate from the adsorbent surface to its interior pores (pore diffusion) and (iv) binding of the adsorbate on the active sites of the adsorbent. Of these steps, the second and third are the slowest ones. Thus, adsorption process of manganese onto PAN/HDTMA/ KCuHCF may be governed by film diffusion or intraparticle diffusion. To discriminate between them, the adsorption kinetic data given in Figure 5 are by the following WeberMorris kinetic model [34]:

$$
Q_{t}=K_{3} t^{0.5}+C
$$

where $K_{3}\left(\mathrm{mg} / \mathrm{g} \mathrm{min}^{0.5}\right)$ is the Weber-Morris rate constant and $C$ is the intercept $(\mathrm{mg} / \mathrm{g})$ which is proportional to the thickness of the boundary layer. For intraparticle diffusion mechanism, the plot of $Q_{t}$ versus $t^{0.5}$ should give a straight line passing through the origin. Figure 7A shows that fitting of manganese kinetic data to the Weber-Morris kinetic model produced two line segments. The first one can be attributed to the intraparticle diffusion, while the second one is ascribed to the equilibrium. The WeberMorris kinetic parameters $\left(K_{3}\right.$ and $\left.C\right)$ are calculated from the slope and intercept of the intraparticle diffusion line segments, which had high correlation coefficients $\left(R^{2}=0.951\right.$ and 0.989 for 55 and $137 \mathrm{mg} / \mathrm{L}$, respectively) as shown in Table 1. Figure 7A demonstrates that straight lines passing through the origin could not be obtained by applying Weber-Morris equation, which is contradictory to the requirement of this model. Consequently, adsorption of manganese onto PAN/HDTMA/KCuHCF is not controlled by intraparticle diffusion. As shown, the diffusion mechanism of the present adsorption process could not be determined. Therefore, the kinetic data depicted in Figure 5 are further analyzed by the Boyd kinetic model (Eq. (12)), which is written as [35]:

$$
B t=-0.4977-\ln \left(1-\frac{Q_{t}}{Q_{e}}\right)
$$

where $B t$ is a mathematical function of the fraction of adsorbate adsorbed at different tine. This model states that the adsorption process is governed by intraparticle diffusion mechanism if the plot of $B t$ versus $t$ yields straight lines passing through the origin. If not, it is controlled by film diffusion. The linear plots (Figure 7B) as well as the
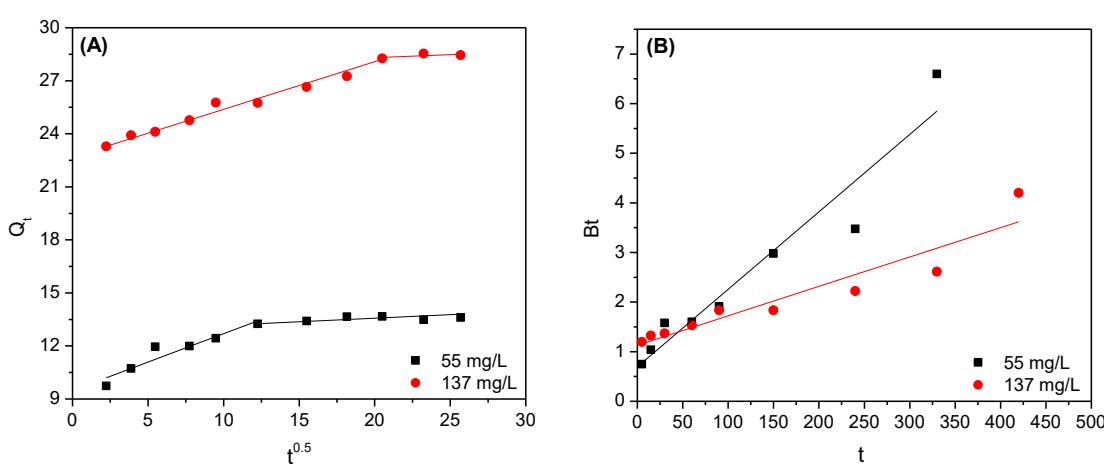

Figure 7: Weber-Morris (A) and Boyd (B) plots for adsorption of 55 and $137 \mathrm{mg} / \mathrm{L}$ manganese onto PAN/HDTMA/KCUHCF composite. 
data given in Table 1 illustrate that applying this model to the kinetic data of manganese resulted into unsatisfactory correlation coefficients $\left(R^{2}=0.919\right.$ for $55 \mathrm{mg} / \mathrm{L}$ and 0.877 for $137 \mathrm{mg} / \mathrm{L}$ ). The non-zero intercept of the plots (intercept $=0.694$ and 1.131 for 55 and $137 \mathrm{mg} / \mathrm{L}$, respectively) along with the previous finding indicated that adsorption process of manganese onto PAN/HDTMA/KCuHCF composite is controlled by film diffusion.

\subsection{Thermodynamic studies}

In order to estimate the values of enthalpy change $\left(\Delta \mathrm{H}^{0}\right)$, entropy change $\left(\Delta S^{\circ}\right)$ and free energy change $\left(\Delta G^{0}\right)$, adsorption processes of cobalt and manganese were calculated at different temperatures $\left(25,35,45\right.$ and $\left.60^{\circ} \mathrm{C}\right)$. These parameters are calculated by the following relations [36]:

$$
\begin{aligned}
\ln K_{d} & =\frac{\Delta S^{o}}{R}-\frac{\Delta H^{o}}{R T} \\
\Delta G^{o} & =-R T \ln K_{d}
\end{aligned}
$$

where $R$ is the universal gas constant $(R=0.008314 \mathrm{~kJ} /$ mol), $T$ is the absolute temperature $(K)$ and $K_{\mathrm{d}}$ is the distribution coefficient $(\mathrm{mL} / \mathrm{g})$. The values of $\Delta \mathrm{H}^{\circ}$ and $\Delta \mathrm{S}^{\circ}$ are calculated from the slope and intercept of the linear plots of $\ln K_{d}$ versus 1/T (Figure 8). Regarding this figure, it can be seen that straight lines with high correlation coefficients $\left(R^{2}=0.965\right.$ for cobalt and 0.973 for manganese, Table 2$)$. The calculated values of $\Delta \mathrm{H}^{\circ}$ and $\Delta \mathrm{S}^{\circ}$ for the studied ions are given in Table 2. The positive values of $\Delta \mathrm{H}^{\circ}$ suggested that adsorption processes of cobalt and manganese onto

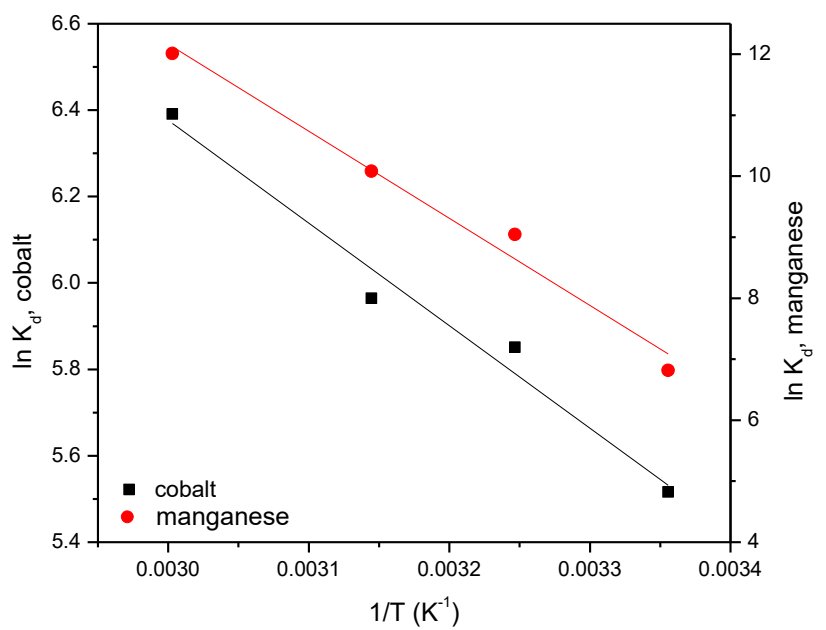

Figure 8: Plots of $\ln \mathrm{K}_{d}$ versus $1 / \mathrm{T}$ for adsorption of cobalt and manganese onto PAN/HDTMA/KCuHCF composite.
Table 2: Thermodynamic parameters for adsorption of cobalt and manganese onto PAN/HDTMA/KCuHCF composite.

\begin{tabular}{lrrrrr}
\hline Adsorbate & $\begin{array}{r}\text { Temperature } \\
(\mathbf{K})\end{array}$ & $\begin{array}{r}\Delta \mathbf{G}^{\mathbf{0}} \\
(\mathbf{k J} / \mathbf{m o l})\end{array}$ & $\begin{array}{r}\Delta \mathbf{H}^{\mathbf{0}} \\
(\mathbf{k J} / \mathbf{m o l})\end{array}$ & $\begin{array}{r}\Delta \mathbf{S}^{\mathbf{0}} \\
(\mathbf{k J} / \mathbf{m o l} \\
\mathbf{K})\end{array}$ & $\boldsymbol{R}^{2}$ \\
\hline Cobalt & 298 & -13.634 & 19.742 & 0.112 & 0.965 \\
& 333 & -17.554 & & & \\
& 343 & -19.674 & & & \\
Manganese & 358 & -20.354 & & & \\
& 298 & -17.475 & 118.711 & 0.457 & 0.973 \\
& 333 & -33.470 & & & \\
& 343 & -38.041 & & & \\
\hline
\end{tabular}

PAN/HDTMA/KCuHCF composite are endothermic, while the positive values of $\Delta S^{\circ}$ (0.112 for cobalt and 0.457 for manganese) indicated the increase of randomness at the solid-liquid interface. The present adsorption processes of cobalt and manganese are found to be spontaneous as shown by the negative values of $\Delta \mathrm{G}^{\circ}$.

\subsection{Equilibrium studies}

Adsorption isotherms, the relation between the equilibrium concentration and the adsorbed amount of adsorbate, for cobalt and manganese (Figure 9) are obtained at $\mathrm{pH} 3.3$ and fixed temperature of $25^{\circ} \mathrm{C}$. This figure shows that the adsorbed amounts of the studied toxicants are increased with increasing their equilibrium concentrations, which is attributed to the increase of mass driving force.

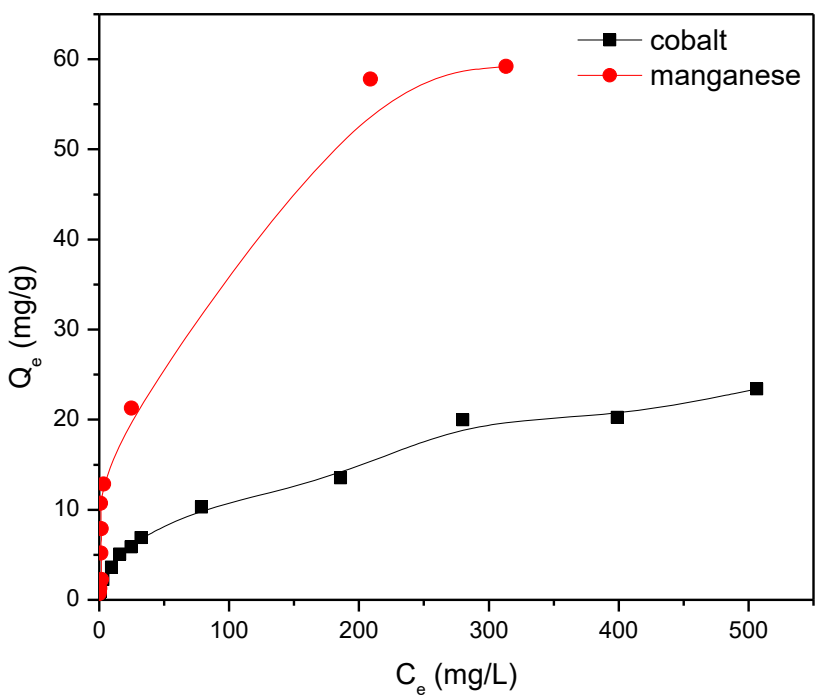

Figure 9: Adsorption isotherms of cobalt and manganese onto PAN/ HDTMA/KCuHCF composite. 

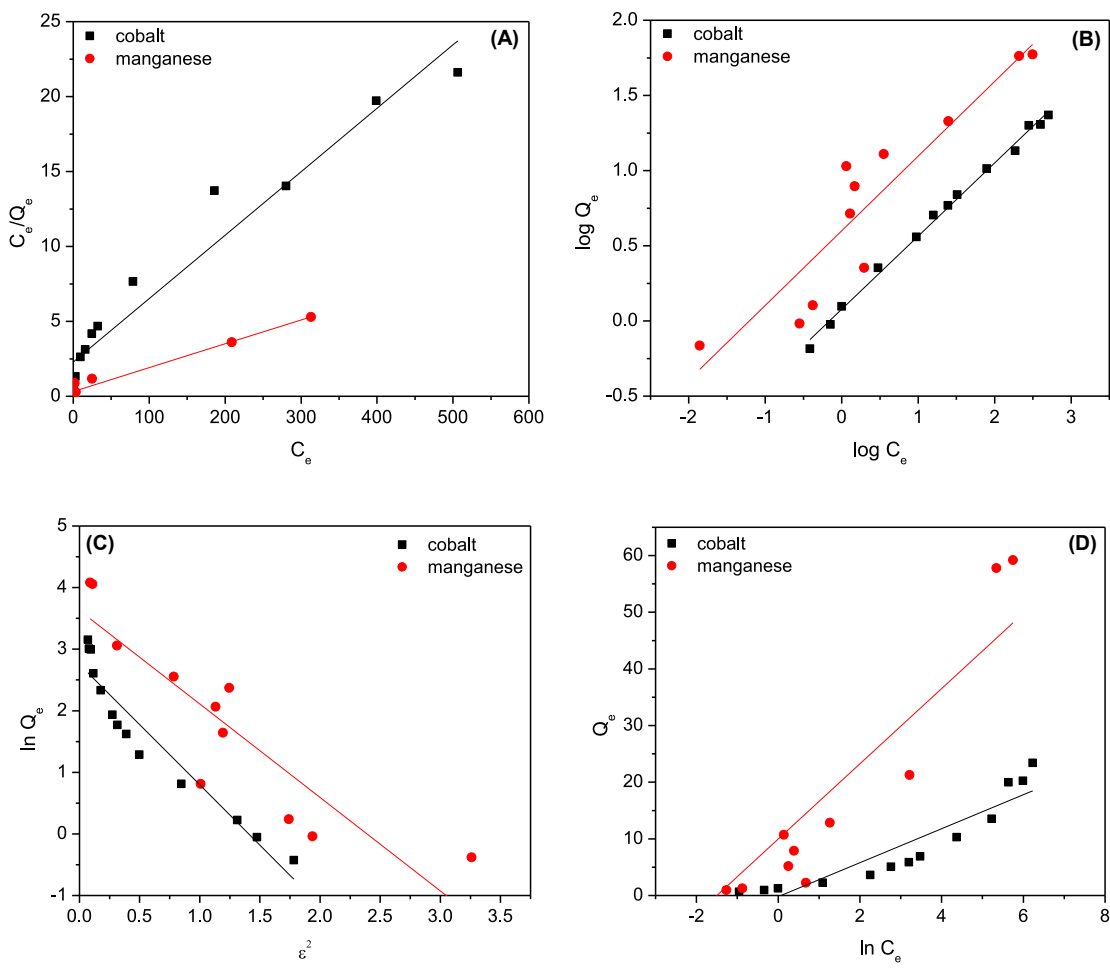

Figure 10: Langmuir (A), Freundlic (B), D-R (C) and Temkin (D) plots for adsorption of cobalt and . manganese onto PAN/HDTMA/ KCuHCF composite.

Table 3: Isotherm parameters for adsorption of cobalt and manganese onto PAN/HDTMA/KCuHCF composite.

\begin{tabular}{llrr}
\hline Model & Parameter & Cobalt & Manganese \\
\hline Langmuir model & $K_{L}(\mathrm{~L} / \mathrm{mg})$ & 0.018 & 0.049 \\
& $Q_{m 1}(\mathrm{mg} / \mathrm{g})$ & 23.629 & 62.854 \\
& $R^{2}$ & 0.947 & 0.975 \\
Freundlich model & $K_{\mathrm{F}}\left(\mathrm{mg}^{1-\mathrm{n}} \mathrm{L}^{\mathrm{n}} / \mathrm{g}\right)$ & 1.197 & 3.979 \\
& $1 / n$ & 0.486 & 0.497 \\
& $R^{2}$ & 0.995 & 0.839 \\
D-R model & $Q_{\mathrm{m} 2}(\mathrm{mg} / \mathrm{g})$ & 15.703 & 37.637 \\
& $K_{D R}(\mathrm{~mol} / \mathrm{kJ})^{2}$ & 1.957 & 1.518 \\
Temkin model & $R^{2}$ & 0.911 & 0.781 \\
& $A_{T}(L / g)$ & 0.934 & 4.695 \\
& $B_{T}$ & 2.998 & 6.644 \\
& $R^{2}$ & 0.839 & 0.767 \\
\hline
\end{tabular}

To describe the adsorption mechanism for binding of cobalt and manganese with PAN/HDTMA/KCuHCF, the equilibrium isotherm data given in Figure 9 are modeled using four of the most frequently adsorption isotherm models. These models are Langmuir [37], Freundlich [38], Dubinin-Radushkevich [39] and Temkin [40]. The linearized forms of these models are given by Eqs. (15)-(18), respectively:

$$
\begin{gathered}
\frac{C_{e}}{Q_{e}}=\frac{1}{Q_{m 1} K_{L}}+\frac{C_{e}}{Q_{m 1}} \\
\log Q_{e}=\log K_{F}+\frac{1}{n} \log C_{e} \\
\ln Q_{e}=\ln Q_{m 2}-K_{D-R} \epsilon^{2} \\
Q_{e}=B \ln A+B \ln C_{e}
\end{gathered}
$$
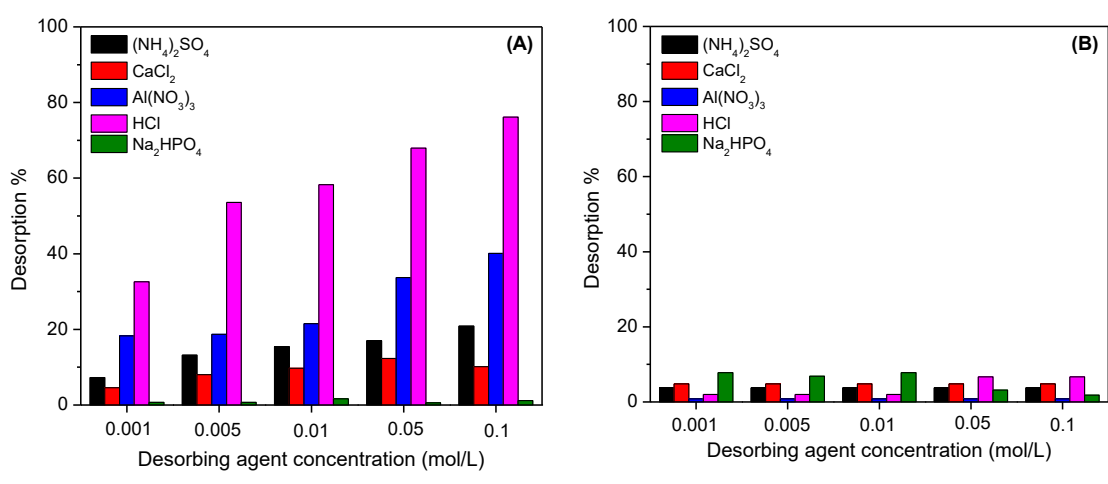

Figure 11: Desorption of cobalt $(A)$ and manganese (B) loaded onto PAN/HDTMA/ KCuHCF using different desorbing agents at various concentrations. 
where $C_{\mathrm{e}}$ is the equilibrium concentration of adsorbate $(\mathrm{mg} /$ $\mathrm{L}), Q_{\mathrm{m} 1}$ and $Q_{\mathrm{m} 2}$ are the adsorption capacity of adsorbent $(\mathrm{mg} /$ $\mathrm{g})$, and $K_{\mathrm{L}}(L / \mathrm{mg}), K_{\mathrm{F}}\left(\mathrm{mg}^{1-\mathrm{n}} \mathrm{L}^{\mathrm{n}} / \mathrm{g}\right), K_{\mathrm{D}-\mathrm{R}}(\mathrm{mol} / \mathrm{kJ})^{2}$ and $A(L / \mathrm{g})$ are the Langmuir, Freundlich, D-R and Temkin constants, respectively. The parameters $n$ and $B$ are related to the heterogeneity of adsorption sites and heat of adsorption respectively. Linear fittings of the adsorption equilibrium data of cobalt and manganese onto PAN/HDTMA/KCuHCF composite to the abovementioned adsorption isotherm models are shown in Figure 10 (A-D). The calculated adsorption isotherm parameters as well as the correlation coefficient value $\left(R^{2}\right)$ for each plot are given in Table 3 . Regarding the $R^{2}$ value recorded in this table for cobalt, it can be seen that it follows the order of Freundlich $\left(R^{2}=0.995\right)>$ Langmuir $\left(R^{2}=0.947\right)>\mathrm{D}-\mathrm{R}\left(R^{2}=0.934\right)>$ Temkin $\left(R^{2}=0.839\right)$. While for manganese it follows the order of Langmuir $\left(R^{2}=0.975\right)>$ Freundlich $\left(R^{2}=0.839\right)>\mathrm{D}-\mathrm{R}$ $\left(R^{2}=0.781\right)>$ Temkin $\left(R^{2}=0.767\right)$. Accordingly, Freundlich and Langmuir isotherm models are the best models for fitting the equilibrium isotherms of cobalt and manganese, respectively. This finding suggested that cobalt ions are physisorbed onto PAN/HDTMA/KCuHCF composite, while manganese ions are chemisorbed.

\subsection{Desorption study}

Desorption results of cobalt and manganese ions loaded onto PAN/HDTMA/KCuHCF composite at different concentrations of $\left(\mathrm{NH}_{4}\right)_{2} \mathrm{SO}_{4}, \mathrm{CaCl}_{2}, \mathrm{Al}\left(\mathrm{NO}_{3}\right)_{3}, \mathrm{HCl}$ and $\mathrm{Na}_{2} \mathrm{HPO}_{4}$ are shown in Figure 11A,B, respectively. The data given in Figure 11A demonstrate that $\mathrm{Na}_{2} \mathrm{HPO}_{4}$ failed to desorb cobalt where no desorption percentages are recorded in this figure. While, it is increased with increasing the concentration of the other studied desorbents and reached to about 10, 20, 40 and $76 \%$ using $\mathrm{CaCl}_{2},\left(\mathrm{NH}_{4}\right)_{2} \mathrm{SO}_{4}, \mathrm{Al}\left(\mathrm{NO}_{3}\right)_{3}$ and $\mathrm{HCl}$, respectively. On the other hand, the studied desorbing agents had no ability to desorb manganese-loaded onto PAN/HDTMA/KCuHCF where the maximum desorption percentage was below $8 \%$. Regarding the data depicted in Figure 11A,B, it can be obviously deduced that manganese ion is strongly bound to PAN/HDTMA/KCuHCF composite than cobalt ion. This finding agrees well with the high values of free energy change $\left(\Delta \mathrm{G}^{0}=-17.475\right.$ to $\left.-44.895 \mathrm{~kJ} / \mathrm{mol}\right)$ and enthalpy change $\left(\Delta \mathrm{H}^{\mathrm{o}}=118.711 \mathrm{~kJ} / \mathrm{mol}\right)$ tabulated in Table 2 for manganese when compared to those of cobalt $\left(\Delta \mathrm{G}^{0}=-13.634\right.$ to $-20.354 \mathrm{~kJ} / \mathrm{mol}$ and $\left.\Delta \mathrm{H}^{0}=19.742 \mathrm{~kJ} / \mathrm{mol}\right)$. Further comparing the data given in Figure 11A,B pointed out that the successful desorption percentage achieved for cobalt using $0.1 \mathrm{~mol} / \mathrm{L} \mathrm{HCl}$ could not be ascribed to dissolution of the composite. Alternatively, it is attributed to the replacement of cobalt ions with hydrogen ions.

\section{Conclusions}

PAN/HDTMA/KCuHCF composite is evaluated as a bifunctional adsorbent for simultaneous removal of radiocobalt and manganese from aqueous solutions. The effect of the solution $\mathrm{pH}$ showed that the employed composite had the ability to simultaneously remove the concerned (radio)toxicants in the $\mathrm{pH}$ range 2.5-6 at an adsorbent mass of $4 \mathrm{~g} / \mathrm{L}$. Adsorption kinetics of radiocobalt, at the studied concentrations (30 and $60 \mathrm{mg} / \mathrm{L}$ ), was found to be fast where almost complete removal was achieved in the first minute. While for 55 and $137 \mathrm{mg} / \mathrm{L}$ manganese, the equilibrium was attained at 330 and 410 min, respectively. Of the studied kinetic models, the pseudo-second-order was the best one for describing the adsorption kinetic data of manganese onto PAN/HDTMA/KCuHCF composite. Based on the results obtained by applying Boyd kinetic model, adsorption process of manganese was controlled by film diffusion. Freundlich and Langmuir isotherm models were the best models for fitting the equilibrium isotherms of cobalt and manganese, respectively. Various desorbing agents were evaluated for desorption of cobalt and manganese loaded onto PAN/HDTMA/KCuHCF composite and the results indicated that none of them had the ability to effectively desorb manganese ion. For cobalt, maximum desorption percentage of $76 \%$ was obtained by hydrochloric acid.

Author contribution: All the authors have accepted responsibility for the entire content of this submitted manuscript and approved submission.

Research funding: None declared.

Conflict of interest statement: The authors declare no conflicts of interest regarding this article.

\section{References}

1. Zhu Y., Hu J., Wang J. Removal of $\mathrm{Co}^{2+}$ from radioactive wastewater by polyvinyl alcohol (PVA)/chitosan magnetic composite. Prog. Nucl. Energy 2014, 71, 172.

2. He M., Zhu Y., Yang Y., Han B., Zhang Y. Adsorption of cobalt(II) ions from aqueous solutions by palygorskite. Appl. Clay Sci. 2011, 54, 292.

3. Keyvani F., Rahpeima S., Javanbakht V. Synthesis of EDTA-modified magnetic activated carbon nanocomposite for removal of permanganate from aqueous solutions. Solid State Sci. 2018, 83, 31. 
4. Tachibana Y., Suzuki T., Nogami M., Nomura M., Kaneshiki T. Syntheses of tannic acid- type organic composite adsorbents for simultaneous removal of various types of radionuclides in seawater. J. Radioanal. Nucl. Chem. 2018, 318, 429.

5. Luo Q., Jiang D., Hou D., Chen W., Hu X., He Y. Effective adsorption of metal ions by modified clinoptilolite zeolite from simulated radioactive solution. J. Radioanal. Nucl. Chem. 2019, 319, 437.

6. Tachibana Y., Kaneshiki T., Nomura M., Suzuki T. Adsorption behavior of radionuclides using novel tannic acidtype resin embedded in high-porous silica beads in seawater. J. Ion Exchange 2014, 25, 199.

7. Tachibana Y., Nogami M., Nomura M., Suzuki T. Simultaneous removal of various iodine species in aqueous solutions of high salt concentrations using novel functional adsorbents. J.

Radioanal. Nucl. Chem. 2016, 307, 1911.

8. Mahmoud M.R., Soliman M.A., Allan K.F. Adsorption behavior of samarium(III) from aqueous solutions ontoPAN@SDS core-shell polymeric adsorbent. Radiochim. Acta 2015, 103, 443.

9. Mahmoud M.R., Soliman M.A., Rashad G.M. Performance appraisal of foam separation technology for removal of Co(II)EDTA complexes intercalated into in-situ formed Mg-Al layered double hydroxide from radioactive liquid waste. Chem. Eng. J. 2017, 326, 781.

10. Shakir K., Ghoneimy H.F., Hennawy I.T., Elkafrawy A.F., Beheir S.G., Refaat M. Simultaneous removal of chromotrope 2B and radionuclides from mixed radioactive process wastewater using organo-bentonite. Eur. J. Chem. 2011, 2, 83.

11. Hamoud M.A., Allan K.F., Sanad W.A., Saad E.A., Mahmoud M.R. Synthesis of PAN/ferrocyanide composite incorporated with cetrimonium bromide and its employment as a bifunctional adsorbent for coremoval of $\mathrm{Cs}^{+}$and $\mathrm{HCrO}_{4}^{-}$from aqueous solutions. J. Radioanal. Nucl. Chem. 2020, 324, 647.

12. Soliman M.A., Rashad G.M., Mahmoud M.R. Development of the adsorption capability of MCM-41 particles synthesized at room temperatureusing 8-hydroxyquinoline-5- sulfonic acid for removal of $\mathrm{Co}(\mathrm{II})$ and $\mathrm{Cr}(\mathrm{VI})$ in binary systems. Chem. Eng. Res. Des. 2019, 144, 459.

13. Mahmoud M.R., Seliman A.F. Evaluation of silica/ferrocyanide composite as a dual-function material for simultaneous removal of ${ }^{137} \mathrm{Cs}^{+}$and ${ }^{99} \mathrm{TcO}_{4}^{-}$from aqueous solutions. Appl. Radiat. Isot. 2014, 91, 141.

14. Mahmoud M.R., Lazaridis N.K. Simultaneous removal of nickel(II) and chromium(VI) from aqueous solutions and simulated wastewaters by foam separation. Separ. Sci. Technol. 2015, 50, 1421.

15. Yan R., Luo D., Fu C., Wang Y., Zhang H., Wu P., Jiang W. Harmless treatment and selective recovery of acidic $\mathrm{Cu}(\mathrm{II})-\mathrm{Cr}(\mathrm{VI})$ hybrid wastewater via coupled photo-reduction and ion exchange. Separ. Purif. Technol. 2020, 234, 116130.

16. Matos L.P., Costa P.F., Moreira M., Gomes C.S., Silva S.Q., Gurgel L.V.A., Teixeira M.C. Simultaneous removal of sulfate and arsenic using immobilized non-traditional SRB mixed culture and alternative low-cost carbon sources. Chem. Eng. J. 2018, 334, 1630.

17. Li H., Chen Y., Long J., Jiang D., Liu J., Li S., Qi J., Zhang P., Wang J., Gong J., Wu Q., Chen D. Simultaneous removal of thallium and chloride from a highly saline industrial wastewater using modified anion exchange resins. J. Hazard Mater. 2017, 333, 179.
18. Yan L., Wang W, Li X., Duan J, Jing C. Evaluating adsorption media for simultaneous removal of arsenate and cadmium from metallurgical wastewater. J. Environ. Chem. Eng. 2016, 4, 2795.

19. Chen F., Wu Q., Lü Q., Xu Y., Yu Y. Synthesis and characterization of bifunctional mesoporous silica adsorbent for simultaneous removal of lead and nitrate ions. Separ. Purif. Technol. 2015, 151, 225.

20. He D., Gu S., Ma M. Simultaneous removal and recovery of cadmium (II) and $\mathrm{CN}^{-}$from simulated electroplating rinse wastewater by a strip dispersion hybrid liquid membrane (SDHLM) containing double carrier. J. Membr. Sci. 2007, 305, 36.

21. Nilchi A., Saberi R., Moradi M., Azizpour H., Zarghami R. Adsorption of cesium on copper hexacyanoferrate-PAN composite ion exchanger from aqueous solution. Chem. Eng. J. 2011, 172, 572.

22. Chauque E.F.C., Dlamini L.N., Adelodun A.A., Greyling C.J., Ngila J.C. Modification of electrospun polyacrylonitrile nanofibers with EDTA for the removal of $\mathrm{Cd}$ and $\mathrm{Cr}$ ions from water effluents. Appl. Surf. Sci. 2016, 369, 19.

23. Xu G., Zhao Y., Hou L., Cao J., Tao M., Zhang W. A recyclable phosphinic acid functionalized polyacrylonitrile fiber for selective and efficient removal of $\mathrm{Hg}^{2+}$. Chem. Eng. J. 2017, 325, 533.

24. Yu D.-G., Williams G.R., Gao L.-D., Bligh S.W.A., Yang J.-H., Wang $X$. Coaxial electrospinning with sodium dodecylbenzene sulfonate solution for high quality polyacrylonitrile nanofibers. Colloid. Surface. Physicochem. Eng. Aspect. 2012, 396, 161.

25. Boguslavsky L., Baruch S., Margel S. Synthesis and characterization of polyacrylonitrile nanoparticles by dispersion/ emulsion polymerization process. J. Colloid Interface Sci. 2005, 289, 71.

26. Rashad G.M., Mahmoud M.R., Soliman M.A. Combination of coprecipitation and foam separation processes for rapid recovery and preconcentration of cesium radionuclides from water systems. Process Saf. Environ. Protect. 2019, 130, 163.

27. Chang C.-Y., Chau L.-K., Hu W.-P., Wang C.-Y., Liao J.-H. Nickel hexacyanoferrate multilayers on functionalized mesoporous silica supports for selective sorption and sensing of cesium. Microporous Mesoporous Mater. 2008, 109, 505.

28. Rosen J. M. Surfactants and Interfacial Phenomena, 3rd ed.; John Wiley \& Sons: Hoboken, New Jersey, 2004.

29. Lee Y., Tebo B.M. Cobalt(II) oxidation by the marine manganese(II)-0xidizing Bacillus sp. strain SG-1. Appl. Environ. Microbiol. 1994, 60, 2949.

30. Chen L., Yu S., Liu B., Zuo L. Removal of radiocobalt from aqueous solution by different sized carbon nanotubes. J. Radioanal. Nucl. Chem. 2012, 292, 785.

31. Ho Y.S., McKay G. Pseudo-second order model for sorption process. Process Biochem. 1999, 34, 451.

32. Lagergren S. About the theory of so-called adsorption of soluble substances. Kungliga Suenska Vetenskapsakademiens Handlingar 1898, 241, 1.

33. Rashad G.M., Mahmoud M.R., Elewa A.M., Metwally E., Saad E.A. Removal of radiocobalt from aqueous solutions by adsorption onto low-cost adsorbents. J. Radioanal. Nucl. Chem. 2016, 309, 1065.

34. Weber W.J., Morris J.C. Kinetics of adsorption on carbon from solution. J. Sanit. Eng. Div. Am. Soc. Civ. Eng. 1963, 89, 31. 
35. Boyd G.E., Adamson A.W., Myers L.S. The exchange adsorption of ions from aqueous solutions by organic zeolites. II. Kinetics. J. Am. Chem. Soc. 1947, 69, 2836.

36. Mahmoud M.R., Rashad G.M., Elewa A.M., Metwally E., Saad E.A. Optimization of adsorption parameters for removal of ${ }^{152+154} \mathrm{Eu}$ (III) from aqueous solutions by using $\mathrm{Zn}$-Cu-Ni ternary mixed oxide. J. Mol. Liq. 2019, 291, 111257.

37. Langmuir L. Adsoption of gases on plane surfaces of glass, mica and platinum. J. Am. Chem. Soc. 1918, 40, 1361.
38. Freundlich H.M.F. Over the adadsorption in solution. Z. Phys. Chem. 1906, 57A, 385.

39. Dubinin M.M., Radushkevich L.V. Equation of thecharacteristic curve of activated charcoal. Proceedings of theAcademy of Sciences USSR. Phys. Chem. Sect. 1947, 55, 331.

40. Temkin M.J., Pyzhev V. Kinetics of ammonia synthesis on promoted iron catalysts. Acta Physiochim. URSS 1940, 12, 327. 